\section{THE USE OF CARBON DIOXID SNOW IN THE TREATMENT OF NEVI AND OTHER LESIONS OF THE SKIN.}

\author{
A PRELIMINARY REPORT. \\ WIJLIAM ALLEN PUSEY, M.D. \\ CIIICAGo.
}

The purpose of this communication is to call attention to the use of fromen carbon dioxid for the destruction of lesions in the skin or for producing a violent inflammatory reaction in such lesions. Its action, of course, depends on its intense cold and on the effect produced by freezing.

Since the idea occurred to me, eighteen months ago, I have used carbon dioxid as a destructive agent in various lesions of the skin. It furnishes a convenient and effective method of removing warts, calluses, senile keratoses and other such lesions. In the case of senile keratoses it is, I believe, an addition of some value to our methods of treatment.

I wish, however, especially to call attention to its use in certain intractable conditions, notably nevi.

The first case here reported illustrates what can be lone in pigmented nevus with carbon dioxid. In this (ase a black hairy nevus occupied one-half of the forehead and a large part of the cheek in a young girl (Fig. 1). At the time of beginning treatment the skin was black, thick and covered by a rough, wart-like epidermis; over the whole there was a very abundant growth of long, coarse, black hair. I first proceeded to remove the hair with $x$-rays; this I was able to do in this case without producing any dermatitis, and without, I may add, any other effect on the lesion. I then began the treatment of the hypertrophic pigmented skin with carbon dioxid. The treatment is not yet complete, but the great improvement at present is evident by contrasting the photograph of the condition at the beginning of the treatment with the present condition of the patient (Fig. 2).

The condition even now is, I am sure, far better than can be obtained in these lesions by any other method of treatment. The site of the original lesions is now covered by a smooth, soft skin, slightly whiter perhaps than normal, but otherwise of normal appearance. There is almost no scarring, the skin is neither elevated nor depressed, and shows no irregularities of texture and no contractions. There are still certain points where the excess of pigment is not entirely removed, but these spots are of faint brown color, and there is no doult that they can be removed by persistence in the applications, for the spots that remain do not require anything like the radical treatment that the original thick pigmented tissue required. The result even now is that a hideous deformity has been replaced by a slight scar.

This is the most extensive case that I have treated and the one which, in my opinion, lends most interest to the method, but I have used the method in the treatment of more than a score of small nevi, lesions varying from the size of a finger nail to the size of a large coin. The results obtained in these smaller lesions is illustrated by the second case which I report: This patient is a little girl who bad an oval nevus, one and one-half inch by one inch in dimensions, situated just below the outer canthus of the left eye and involving part of the lower lid. In this lesion there was some hyperplasia of the connective tissue as well as of the epidermis; the nevus was elevated alout one-sixteenth of an inch, was of dark brown color and was covered by coarse, brown hair from one-half to three-fourths of an inch long. This lesion had treatment only with carbon dioxid, thus showing that the hairs in the lesion can be destroved by the treatment. At present there remains only a superficial sear; it is thin and pliable and of normal color; a half-dozen short hairs are left which can readily be removed by electrolysis. The scar is not visible at a distance of ten feet.

I have also treated several cases of vascular nevus by this method. It is not difficult to destroy the blood vessels in these lesions, and in the cases that I have treated there has been great improvement. The flat lesions can be converted into almost normal colored skin. The greatest difficulty is to aroid making the lesion whiter than normal; with care, however, it is possible, by repeated moderate applications, to destroy just enough blood vessels to leave the skin of almost normal color. In cavernous nevi I believe the method would be successful only in selected cases.

The third case is one of erythematous lupus treated by this method. This patient, four months ago, had over her face and neck numerous disc-shaped patches of erythematous lupus of the size of a coin or larger. The largest area, involving the forehead at the hairy border, was several inches in length and from one-half to one and one-half inches in width. Under the application of carbon dioxid practically all evidences of the disease have disappeared. The border of the large area on the scalp is still slightly infiltrated and red. It will have further treatment. All other patches are apparently well.

Of course no one can prophesy as to the future course of an erythematous lupus, but the present result in this case seems to me to be extraordinarily good. (Subsequently this patient was discharged symptomatically well.) I have also treated several other patches of erythematous lupus in various patients with similarly good results, but no other patient has been so completely treated as this one.

I may add that I have used the treatment in several lesions of lupus vulgaris without success. The freezing effect has apparently not been sufficiently deep in my applications. I have no doubt that nodules of lupus can be destroyed by this method, but I believe it offers us nothing of essential value in the treatment of lupus vulgaris.

The same statement applies perhaps to epithelioma. Epitheliomatous tissue can readily be destroyed with carbon dioxid, and small epitheliomata can be easily removed with it. As I have already indicated, the method is of use in senile keratoses showing beginning epitheliomatous degeneration, but aside from its use in these very superficial lesions I do not believe the method is one of choice in epithelioma.

\section{LIQUID AIR AND LIQUID CARBON DIOXID.}

The intense cold of liquid air has been utilized by a number of investigators in treating various lesions of the skin. Trimbell and Dade in particular in this country have experimented with this method of treatment. But there are strong practical difficulties in the way of the use of liquid air: First, it is not obtainable commercially, so that one's supply of it is uncertain; second, it can not be confined in a closed vessel but must be allowed to evaporate gradually, so that a supply, whether it is used or not, lasts but a short time. On account of these objections the possibility of using carbon dioxid as a substitute for liquid air occurred to me on seeing Dade's demonstration of the use of liquid air 
as a therapeutic measure. Liquid carbon dioxid is obtainable anywhere that soda fountain supplies are sold and can be preserved indefinitely.

Liquid carbon dioxid as obtainable in commerce is not liquid under ordinary atmospheric pressure, but is held in liquefied state under a pressure of approximately 800 pounds to the square inch. When it is drawn from its drum into the air it evaporates so rapidly that it freezes and is deposited in the form of a white snow resembling very closely in appearance ordinary snow. Its freezing point at atmospheric pressure is about $-90 \mathrm{C}$., while the liquefaction point of air under normal pressure is approximately $-180 \mathrm{C}$. Liquid air, therefore, is about twice as cold as carbon dioxid snow, but I am not sure that this is an advantage in its use as a therapeutic agent. It is possible that the effects can not be so accurately controlled. Both freeze the tissues almost instantly on contact. In a limited experience in the use

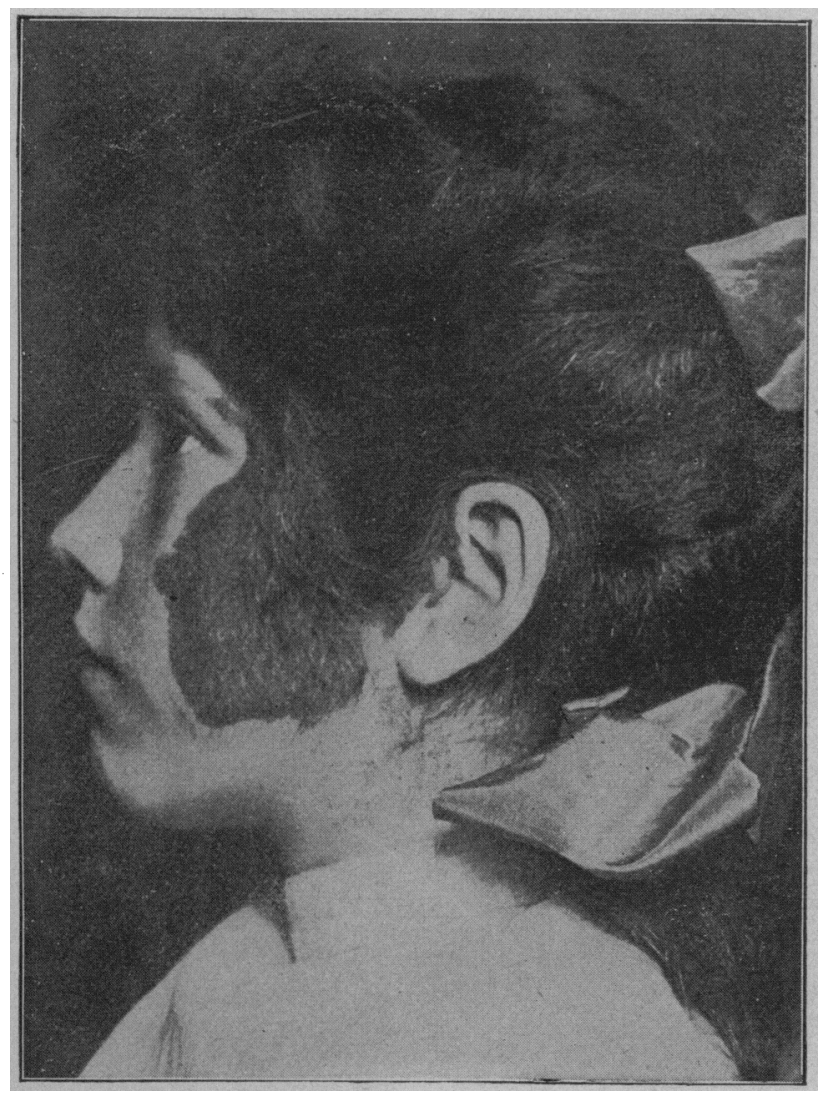

Fig. 1.-Appearance of patient before treatment.

of liquid air I have not found any difference in the action of the two agents.

The principle underlying the use of both of these agents is, of course, the same. This is to produce, by sudden intense freezing, either violent inflammation of the tissues or their destruction. The technic of the use of carbon dioxid as I have carried it out is as follows:

The carbon dioxid snow is collected in a cloth or piece of chamois skin as it escapes from the cylinder. In order to collect it best the cylinder should be tipped up so that the opening is at the lower end. The carbon dioxid is deposited on the cloth in the form of a snow, which can be compressed and handled very much like ordinary snow. The liberation of gas is so rapid that unless the snow is firmly grasped there is a laver of gas between the solid mass and the skin so that it can be easily handled. The snow is pressed between layers of chamois shin into solid masses, as one would make a snowball, and then pared with a knife into whatever shape is desired. It is then held in forceps and applicd to the surface. In treating lesions less than a centimeter square the snow can be pared, or melted between the fingers, into the shape of the lesion. In treating a larger lesion $I$ have found that it is desirable to cut the snow in the shape of square sticks with an end surface not more than a centimeter square. In freezing, the end of the stick is applied. It is best to make the freezing surface of the snow rectangular, in order that adjacent areas when frozen may elosely correspond to cach other without overlapping.

If the agent has any therapeutic usefulness-and I decidedly believe it has-this depends principally on the fact that in it we have a destructive application whose action can be accurately gauged and is therefore controllable. In the next place it is an agent by which

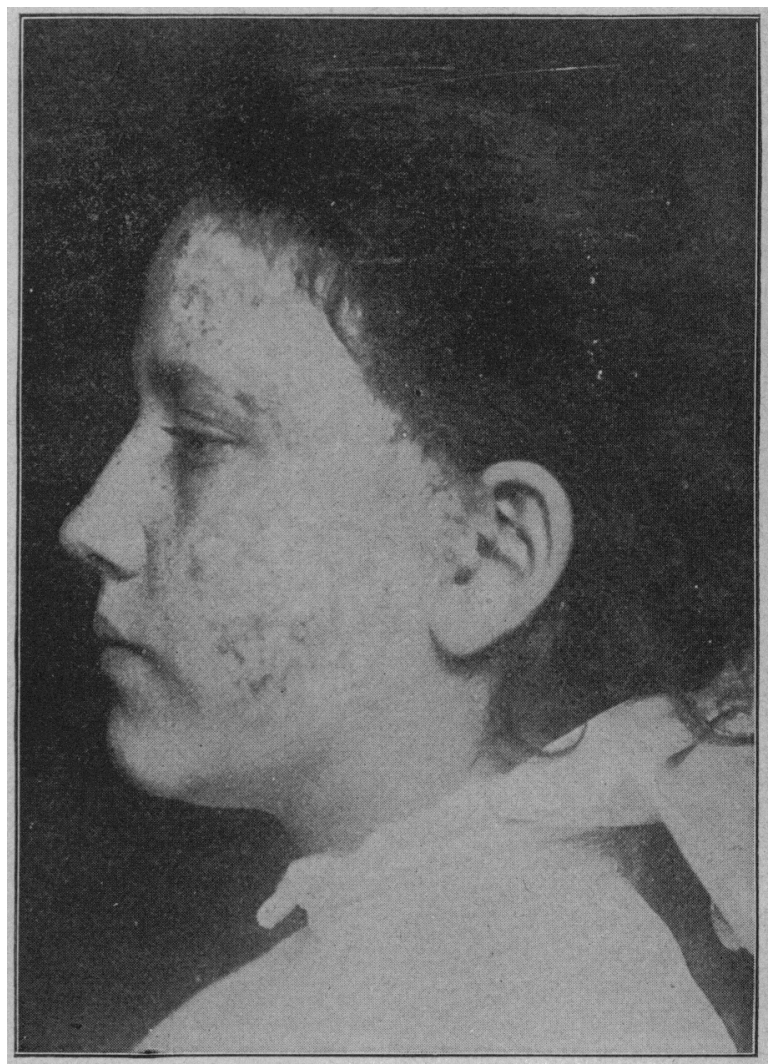

Fig. 2,-Appearance of patient after treatment with carbon dioxid. The remaining pigmentation shows more distinctly in the photograph than it does on the patient's face.

one can produce a violent inflammatory process in the vascular tissues of the skin without completely destroying the overlying epidermis, so that some epidermal cells are left over the lesions to lessen scarring. The effects produced by the application of the agent depend on two factors: first, the amount of pressure exerted, and, second, the duration of the freezing. The stronger the pressure the deeper will the tissues be frozen. Under the maximum amount of pressure which can practically be exerted in using the snow I should say that freezing to the depth of from one-eighth to one-sixth of an inch can be produced in a few seconds. Under ordinary circumstances freezing to the depth of from one-sixteenth to one-twelfth inch is produced. As a rule I exert just enough pressure to fix the snow firmly against the skin, 
but here I vary somewhat according to the effect desired. The depth, and perhaps the suddenness of the freezing with carbon dioxid constitute the difference between this measure and freezing with volatile mixtures which are simply sprayed on the surface. With these there is merely a surface freezing; with the other there is freezing of the tissues to a considerable depth.

\section{DCRATION OF FREEZING.}

The duration of the freezing is, of course, the most important factor. Within a second after the application of the snow the skin is frozen white. If the skin is frozen under slight pressure for from five to ten seconds or more it is converted into a hard, white, frozen mass, like white ice. As a rule, this frozen mass thaws out in about twice the length of application of the carbon dioxid For example, after an application of thirty seconds it requires sixty seconds, approximately, for the mass to thaw. During the freezing there is only a sensation of cold; this is not disagreeable enough, as a rule, to make a child cry. On thawing there is a stinging sensation which is simply disagreeable. This disappears usually within a few. minutes, but may persist for half an hour or more. In one or two minutes after thawing there is a little moisture of condensation on the surface and a slight erythema; in ten minutes there is a beginning wheal, which soon becomes well developed. After an application of from five to ten seconds there will develop in the course of from six to eight hours a sharply circumscribed inflammatory area with vesiculation of the epidermis. . After an application of five seconds the inflammatory products will be absorbed in about five days without crusting and without any scarring whatever. After a freezing of ten seconds the vesiculation will. likely be followed in about three days by the formation of a thin crust; in the course of a week this will disappear with the production of very superficial sclerosis of the upper part of the corium, but without changes in the epidermis-practically without any scarring whatever. These applications of from five to ten seconds are sufficient to remove thin layers of pigment from the skin, or when an inflammatory reaction is desired for therapeutic purposes, as in erythematous lupus. After an application of twenty seconds there is formed in about six or eight hours a superficial tense bulla, which in the course of a few days dries up, leaving a crust that disappears in about ten days. With an application of thirty seconds duration the effect is still more marked; the bulla is followed by a superficial. crust and its disappearance in the course of about two weeks is followed by a slight scarring. With an application of fifty seconds there is formed a tense bulla, which in the course of a week is followed by a closely adherent dry eschar which does not separate for about three weeks. The eschar separates without ulceration and leaves a superficial scar which is smooth, white and not contracted.

In practice I have found applications of from ten to thirty seconds duration the most satisfactory. The effect of these can be gauged accurately, and if one application is not sufficient it can be repeated later. There is almost no scarring from such applications. With longer applications there is a slight amount of white scarring, white because there is destruction of many of the capillaries. In treating a lesion that it is desired to destroy promptly, and under conditions in which a slight amount of scarring makes no difference, a vigorous prolonged single application can be made and all the work done at once. If deep destructive action is de- sired this can be attained by repeating the application on successive days or at longer intervals. Otherwise the application of the snow should not be repeated until the effect of the previous application has disappeared.

\section{Special Article}

\section{TRAVEL NOTES FROM SOUTH AMERICA.}

\author{
NICHOLAS SENN, M.D. \\ CHICAGO.
}

(Continued from page 1281.)

IV.* WORK OF THE NATIONAL BOARD OF PUBLIC HEALTH OF THE REPUBLIC OF BRAZIL.

Since the country was invaded by Europeans nearly four hundred years ago, many hard battles have been fought on the soil of Brazil for possession, power and personal gain and influence. In many of these wars, Justice was blindfolded and victories were won by superior intelligence and greater effec-

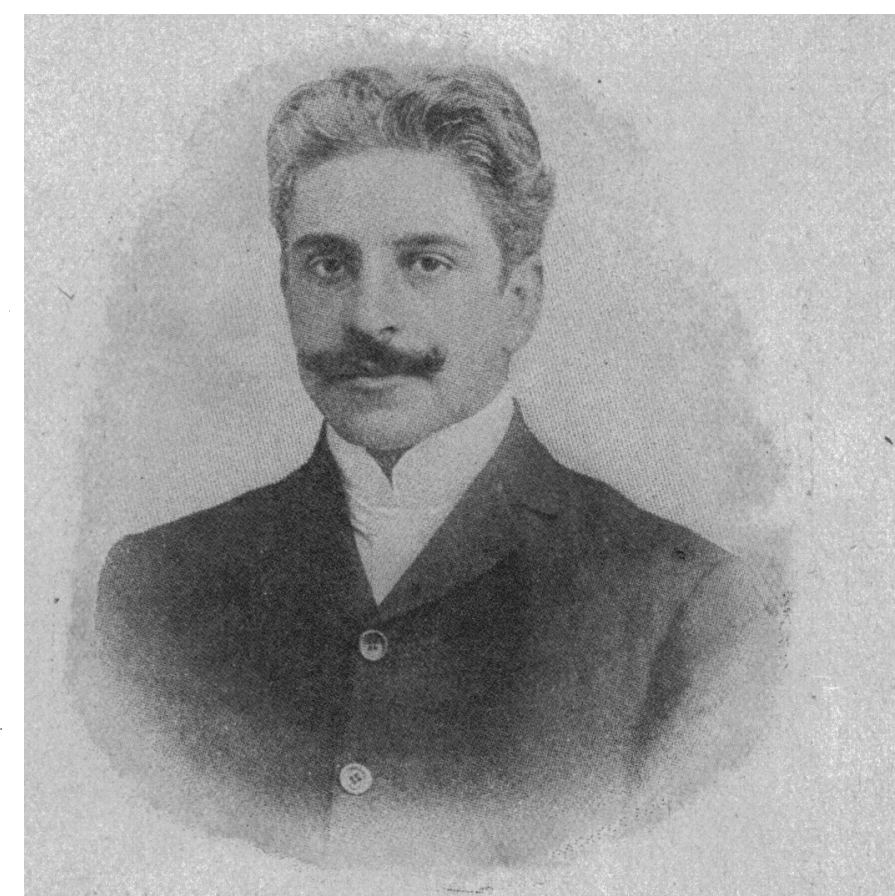

Fig. 8.-Dr. Oswaldo Goncalves Cruz, Director General of Public Health of Brazil.

tiveness of arms, regardless of the causes which led to strife and bloodshed. The greatest and most honorable warfare in which Brazil ever engaged, however, is now being waged, and victory after victory has crowned her fighting forces, armed not with implements of war, but with the silent arms of science, which have destroyed the most formidable foe of the country, the death-dealing microbes of the most dangerous acute transmissible diseases-yellow fever and bubonic plague. What Colonel Gorgas has accomplished in the Canal Zone and the cities of Panama and Colon has been gained by Dr. Oswaldo Cruz (Fig. 8) in Brazil during the last four years. At the head of a Sanitary Corps of 2,200 well-trained and wellequipped men, and with the aid of a large staff of assistants specially trained for their work, he has succeeded in ridding the Brazilian coast of yellow fever and reducing the ravages of bubonic plague to a minimum. These two diseases for years and years have decimated the population of Brazil, clogged the wheels of commerce and seriously impeded the development of her boundless resources. The fear of these diseases

*.This series was commenced September 14. 